\title{
Housing and Child Health in South Africa: The Value of Longitudinal Research
}

\author{
Kenneth Chatindiara, Lochner Marais * and Jan Cloete
}

Citation: Chatindiara, K.; Marais, L.; Cloete, J. Housing and Child Health in South Africa: The Value of Longitudinal Research. Int. J. Environ. Res. Public Health 2022, 19, 2497.

https://doi.org/10.3390/ ijerph19052497

Academic Editor: Paul B. Tchounwou

Received: 19 December 2021 Accepted: 10 February 2022 Published: 22 February 2022

Publisher's Note: MDPI stays neutral with regard to jurisdictional claims in published maps and institutional affiliations.

Copyright: (C) 2022 by the authors. Licensee MDPI, Basel, Switzerland. This article is an open access article distributed under the terms and conditions of the Creative Commons Attribution (CC BY) license (https:// creativecommons.org/licenses/by/ $4.0 /)$.
Centre for Development Support, University of the Free State, Bloemfontein 9300, South Africa; 2017008844@ufs.ac.za (K.C.); CloeteJS@ufs.ac.za (J.C.)

* Correspondence: MaraisJGL@ufs.ac.za

\begin{abstract}
Research investigating the link between housing and health often produces mixed results. It does not always prove that good housing improves health. The results suggest a complex set of factors play a role, and the findings are sometimes contradictory. Two ways of addressing these concerns are longitudinal research, where the relationship between housing and health is measured in the short and medium terms, and a focus on children. We use the children's housing and health data from the five waves of the National Income and Distribution Survey (NIDS) survey in South Africa, 2008 to 2017. We investigate the effect that continued living in informal housing over the five waves has had on these children's health. Our results show a statistically significant relationship between prolonged residence in poor housing and poor health outcomes for some health indicators. The results call for a closer understanding of health issues in housing policy in South Africa.
\end{abstract}

Keywords: housing; child health; longitudinal research

\section{Introduction}

The relationship between housing and health is not always clearly shown by research. We assume that good living conditions are good for health. However, the evidence is mixed at best, with only a few studies pointing to statistically significant relationships. Dependence on cross-sectional surveys and the limited use of longitudinal data mean that many conceptual and methodological gaps remain. Several studies have looked at the relationship between housing and health [1-8]. We argue that longitudinal work is the method most likely to clarify the relationship between housing and health and that more of this kind of work should be performed.

Our study investigates the relationship between the housing conditions in which children grow up and their health later in life. We address the methodological concerns associated with cross-sectional research designs. We compare the housing conditions of children over the five waves of the National Income and Distribution Survey (NIDS) (2008-2017) with their self-reporting of their health in 2017. Although there is increased reference to well-being in the literature, including mental health, we took into account only the physical health indicators.

\section{The Literature}

\subsection{Defining Inadequate Housing and Health}

Mallet et al. define 'precarious housing' as housing to which at least two of three conditions apply: Unsuitability, unaffordability and insecurity [9]. 'Unsuitable housing' means overcrowding, poor physical conditions and an unsafe environment or poor location. 'Unaffordable housing' means the rent or mortgage repayment is too high for the household's monthly income. 'Insecure housing' means insecure tenure and the threat of forced removal. The Constitution of the World Health Organisation (WHO) (1946) defined 'health' as 'a state of complete physical, mental and social well-being and not merely the absence 
of disease or infirmity' [10]. This definition has been accepted since then. We deliberately did not include homelessness because homelessness is an under-developed concept in the South African data and literature. The concepts we use in this paper adequately describe the reality on the ground and as captured in the data.

\subsection{Conceptual Framework}

Socioeconomic and political factors affect health and well-being and health equity. Health equity is defined as the absence of unfair and avoidable or remediable differences in health among population groups defined socially, economically, demographically or geographically. Figure 1 shows a conceptual framework for the relationship between housing and health [11]. We have circled the items of particular relevance to this paper. The WHO framework identifies two main determinants of health and well-being: Structural and intermediary. The structural determinants influence intermediary determinants that eventually influence equity in health and well-being. The structural determinants are a person's socio-political context and socioeconomic position. The intermediary determinants are a person's material circumstances (including living conditions), behaviour, biological and psychosocial factors and the health system itself. We can thus postulate a link between housing policy (a structural determinant), living conditions (an intermediary determinant) and people's health and well-being. This paper focuses only on housing and the related living conditions as an intermediary determinant of health and well-being, while acknowledging the broader influences, such as policy, which are beyond our scope here.

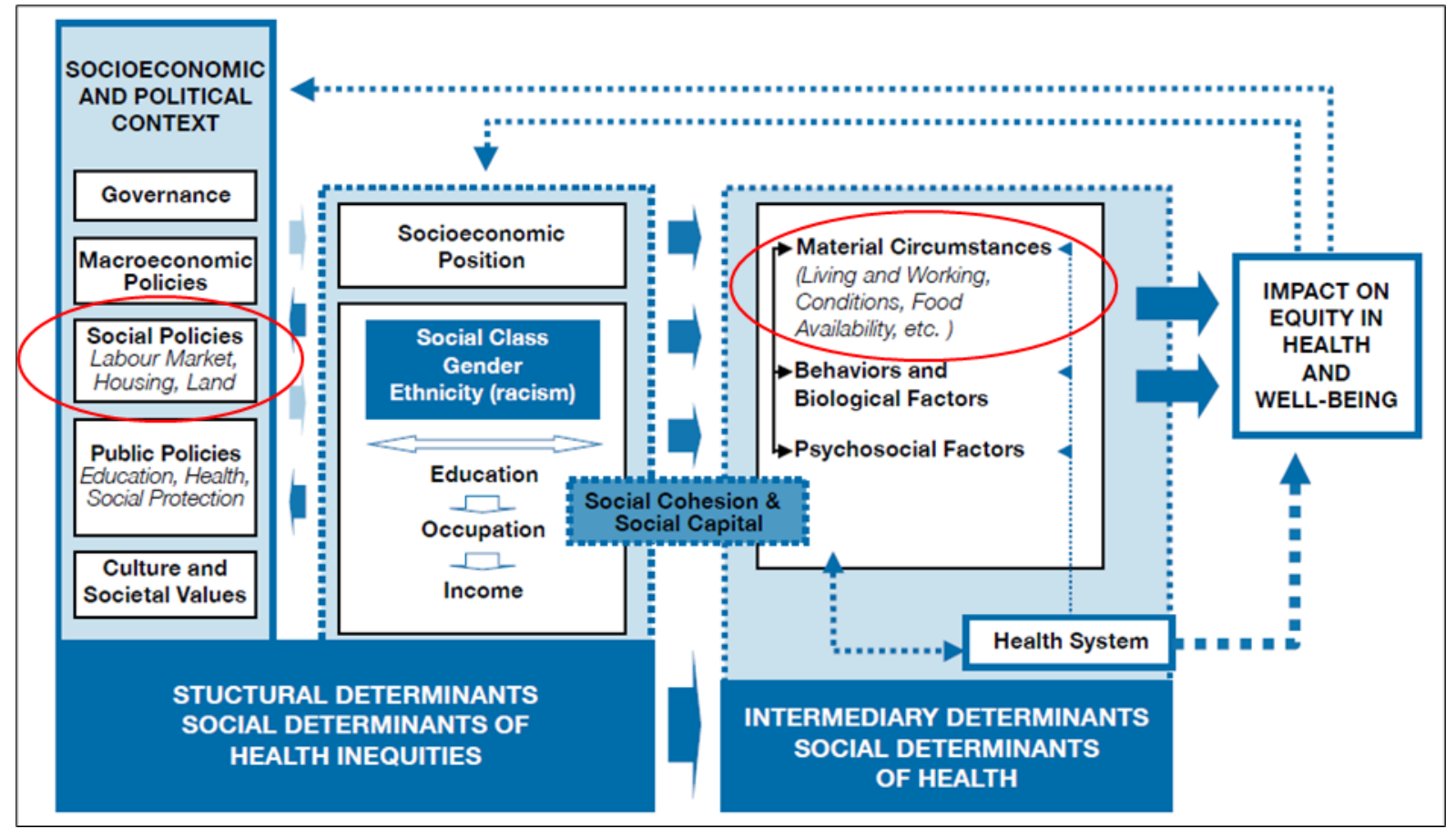

Figure 1. Conceptual framework showing the link between housing and health and well-being [12].

\subsection{Evidence from Research}

\subsubsection{Housing and Health}

Several studies have shown statistical relationships between housing and health [1,3,6,7,13-15]. Bad housing has been shown to increase asthma, lead poisoning, injuries and mental health problems [16,17] and acute respiratory infections in children [18]. In a cross-sectional study of housing conditions and child health in Sweden, Oudin et al. found links between dampness and asthma and between mould and headache [19]. In cross-sectional analyses of demographic health surveys across 33 countries, Tusting et al. found that poor housing 
conditions are likely to cause child mortality since children spend more time at home than adults and are thus more likely to be affected [8].

Socioeconomic factors such as household structure and tenure status have also been shown to affect health. Socioeconomic deprivation and severe household crowding cause psychological distress [4]. Solari and Mare expressed the opinion that the negative effects of being raised in crowded homes can persist throughout life [3]. Howden-Chapman found that homeowners were likely to have better health than people who rent, as tenants are more exposed to housing instability caused by moving from place to place [1]. Using a 2010 postal survey in West Scotland, Ellaway et al. found that housing tenure status (secure housing as opposed to insecure housing) can affect four measures of self-assessed health: Chronic, recent and mental health problems, and health in general. Evaluating the association between the inability to pay a mortgage (an example of unaffordability) and changes in health, Alley et al. found that participants who had fallen behind on their mortgage payments had worse health than those who were up to date [20].

\subsubsection{Children, Housing and Health}

Children are much more prone to respiratory problems than adults. They spend more time on the floor and put objects in their mouths. They have immature immune systems and metabolisms and fewer opportunities to manage their environment. Early-life exposure to chemical, biological and physical agents comes primarily from the home environment or, as we term it in this paper, unsuitable housing [19].

Longitudinal approaches allow the researcher to study the effect of the continued experience of unsuitable housing at different points in the life course [15]. From a longitudinal analysis of data from the UK National Child Development Survey, Marsh et al. found a significant association between poor physical housing and ill health later in life [15]. Using two composite indices, health and housing deprivation, they showed that housing deprivation (unsuitable housing) leads to poorer health outcomes.

Household characteristics are critical for early childhood development and children's health, as the home is where children spend a large proportion of their time, and unsuitable conditions can lead to bad health later in life $[2,15,17,21]$.

Concerning the empirical evidence, the literature identifies three examples of unsuitable housing factors that affect children's health: Household composition, household crowding and the house's physical condition. Household composition determines future education and socio-emotional behaviour. Leventhal and Newman found that single-parent and blended families have short-term adverse effects on children's school achievement and health [22] (a 'blended family', or 'stepfamily', is one in which at least one parent has a child or children who are not related to the spouse or partner biologically or by adoption). Using data from the Botswana Family Health Survey, Ntshebe et al. found a relationship between housing composition, stunting and diarrhea [23]. They found that children not living with both parents were more likely to suffer from stunting and that children living in mother-only households and those with no parents were less likely to have diarrhoea than those living with both parents.

Household crowding is usually measured by the number of occupants divided by the number of rooms. Crowding indicates a socioeconomic disadvantage and creates a stressful home environment [24]. A crowded home affects children, as they have limited space to complete homework or rest, interact with family members, practice skills and develop their own identity [3]. In a study of 10- to 12-year-old children in urban India, Evans et al. found that residential crowding led to high blood pressure in boys and helplessness in girls, but although crowding increased psychological distress, it did not produce serious mental illness [25].

The house's physical condition plays a role in children's health. Dockery et al. found that children aged 0 to 9 living in houses had better socio-emotional outcomes than those living in apartments and townhouses [26]. They also found that children living in houses with good external conditions (rated by the interviewer on a scale from 1 to 4: Badly 
deteriorated, in poor condition, in fair condition, well-kept and in good repair) had better socio-emotional outcomes than those living in houses with poor external conditions. Gifford and Lacombe and Coley et al. also found significant associations between the physical condition of housing and child socio-emotional outcomes [2,27]. Fry found that children who grow up homeless are less likely to perform well in working-memory and decisionmaking tasks than those who grow up in proper housing [28].

\subsection{South African Studies}

\subsubsection{Housing and Health}

Several studies show a relationship between housing attributes and health [29-32]. Marais and Cloete examined the health impacts of the South African housing subsidy programme and found that infrastructure-related factors rather than housing structure affect health outcomes [30]. Nkosi et al., in their analysis of an 11-year panel study undertaken in two suburbs in Johannesburg between 2006 and 2016, found that acute respiratory symptoms were statistically significantly associated with moderately as well as extremely overcrowded houses [32]. Their study further showed that diarrhoea was statistically significantly associated with overcrowding. Shortt and Hammett, in their research into formal and informal housing in the Imizamo Yethu informal settlement in Cape Town, found no statistically significant differences in self-reported physical health but some differences in mental health. In Johannesburg [33], De Wet et al. found, counterintuitively, that people living in informal housing had significantly better health outcomes than those living in formal housing [34]. This was because those living in the informal houses were relatively young and recent migrants.

Crowding is associated with acute respiratory and gastrointestinal symptoms [32]. Using data from the Cape Area Panel Study, Muyeba found that people living in houses constructed by the state's housing subsidies had better physical health (but, counterintuitively, higher occurrences of teenage pregnancy), implying that health improvement results from better housing quality and a better living environment [35]. The Human Sciences Research Council found that HIV is more prevalent in informal than formal urban areas [36]. The high incidence of disease in informal urban areas can be linked to low socioeconomic status. Gibbs et al. note that the legacy of apartheid and high poverty levels have contributed to poor mental health outcomes amongst black South Africans [37].

\subsubsection{Children's Health}

There is very little literature on the effects of housing on children's health in South Africa. Marais et al., in a study of the relationship between housing conditions and the socio-emotional health of orphans and vulnerable children in South Africa, found a positive relationship between living in informal settlements and better socio-emotional health of these children [38]. They found that crowding was more important than settlement type in determining socio-emotional outcomes. Mathee et al. found that despite the benefits of improved housing and settlement development, large numbers of young children in South Africa still live in hazardous environments that threaten their health [31].

There is no formal system focusing on housing and child health in South Africa. However, the Department of Social work often places orphans and vulnerable children with foster parents receiving a care grant. The focus of this system is to keep children in their communities and to ensure adequate housing and care. This would, for example, apply to cases where both parents have died, and there is a child-headed household. The assumption is that foster care will ensure good housing and health. However, there is no guarantee of this in practice.

\section{Materials and Methods}

The association between housing and health is complex. The causal relationship is difficult to establish, as it can be hidden in or influenced by other covariates. Methodologically, it can be difficult to exclude or control confounding variables [39-41]. 


\subsection{Background and Data}

We used longitudinal data from the National Income Dynamics Study (NIDS), the first national household panel study in South Africa. NIDS is a nationally representative sample of over 28,000 individuals in 7300 households. The Southern Africa Labour and Development Research Unit (SALDRU) at the University of Cape Town implemented the first five waves of NIDS, in 2008, 2010, 2012, 2015 and 2017. We used data from all five waves, available from the DataFirst website (http:/ / www.nids.uct.ac.za/ accessed on 14 September 2021). We used Stata Version 14 (StataCorp, College Station, TX, USA) for analysis.

United Nations Children Fund defines a child as any human being below 18 years. Wave 1 of the NIDS dataset, 2008, included 11,226 children aged 0 to 17 [42]. These respondents were then followed for five waves over nine years. By Wave 5, many of these initial participants were not children anymore (for example, a participant who was 16 in Wave 1 would be 25 by Wave 5). Respondents who dropped out of the survey for various reasons were replaced at each wave. We did not use these replacements in our study. The self-reported data on health was obtained from Wave 5 in 2017. The sample is predominately urban, with approximately $60 \%$ of the children in the sample being urban. However, $81 \%$ of those in informal housing were urban. South Africa is also $70 \%$ urbanised.

The paper focuses only on physical health. The hypothesised drivers of physical health are varied and differ significantly from those of mental health. We chose one set of outcomes upon which to focus the paper.

\subsection{Defining Adequate Housing for the Study}

NIDS required respondents to describe the main house that the household occupies. The answers to this question were then categorised into formal and informal housing. 'Informal dwelling in the backyard' and 'informal house on a separate stand' were categorised as informal and all other housing types as formal. For our study, we assumed that informal housing represents inadequate housing and formal housing represents adequate (although we acknowledge that this is not always the case). Table 1 shows the numbers living in the two types of housing.

Table 1. Housing conditions and numbers of people aged 0 to 17 in NIDS Wave 1.

\begin{tabular}{|c|c|c|c|c|c|c|c|c|c|c|}
\hline \multirow{2}{*}{ Type of Housing } & \multicolumn{2}{|c|}{ Wave 1 (2008) } & \multicolumn{2}{|c|}{ Wave 2 (2010) } & \multicolumn{2}{|c|}{ Wave 3 (2012) } & \multicolumn{2}{|c|}{ Wave 4 (2015) } & \multicolumn{2}{|c|}{ Wave 5 (2017) } \\
\hline & Number & $\%$ & Number & $\%$ & Number & $\%$ & Number & $\%$ & Number & $\%$ \\
\hline $0=$ Informal house & 855 & 7.62 & 766 & 7.93 & 649 & 6.58 & 851 & 8.61 & 911 & 9.70 \\
\hline $1=$ Formal house & 10,371 & 92.38 & 8888 & 92.07 & 9207 & 93.42 & 9031 & 91.39 & 8485 & 90.30 \\
\hline Total & 11,226 & 100.00 & 9654 & 100.00 & 9856 & 100.00 & 9882 & 100.00 & 9396 & 100.00 \\
\hline
\end{tabular}

We traced the same 7781 participants over the five waves. Table 2 shows our binary breakdown of inadequate housing and the dummy variables we used in the regression analysis. We considered that living in an informal dwelling for four of the five waves constituted continued experience of poor housing. This was the experience of $669(8.6 \%)$ individuals in the sample.

\subsection{Defining Health Outcomes for the Study}

We used several physical health measures from NIDS as dependent variables, as shown in Table 3. The self-reported answers were binary (yes/no). A value of one was given if the respondent had suffered from a particular symptom in the past 30 days and zero if not. The study used the answers from Wave 5, 2017. The table shows low numbers of reports of these symptoms of poor health except for a fever, body ache, headache and backache. 
Table 2. Housing constructs and variables.

\begin{tabular}{cccc}
\hline Variable & Description & Number & $\%$ \\
\hline & $\begin{array}{c}0=\text { If individual lived in a formal dwelling or for } \\
\text { less than four waves in an informal dwelling }\end{array}$ & 7112 & 91.40 \\
\cline { 2 - 4 } $\begin{array}{c}\text { Continued experience of } \\
\text { poor housing }\end{array}$ & $\begin{array}{c}\text { 1 If individual lived in an informal dwelling for } \\
\text { four or five waves }\end{array}$ & 669 & 8.60 \\
\cline { 2 - 4 } & Total & 7781 & 100.00 \\
\hline
\end{tabular}

Table 3. Summary statistics for poor health outcomes.

\begin{tabular}{ccccc}
\hline Health Indicators & 1 = Yes & \multicolumn{2}{c}{$\mathbf{0 = \text { No }}$} \\
\hline Disease & Number & \% & Number & \% \\
\hline Fever & 1577 & 22.62 & 5395 & 67.38 \\
Persistent cough & 805 & 11.54 & 6168 & 88.46 \\
Coughing blood & 58 & 0.83 & 6476 & 99.17 \\
Chest pain & 498 & 7.14 & 5826 & 92.86 \\
Body ache & 1142 & 16.39 & 4677 & 83.61 \\
Headache & 2299 & 32.96 & 6030 & 67.04 \\
Backache & 938 & 13.46 & 6273 & 86.54 \\
Arthritis & 695 & 9.97 & 6678 & 90.03 \\
Diarrhoea & 295 & 4.23 & 6883 & 95.77 \\
Dysuria & 86 & 1.23 & 6719 & 98.77 \\
Swollen ankles & 257 & 3.68 & 6736 & 96.32 \\
Weight loss & 233 & 3.34 & & 96.66 \\
\hline
\end{tabular}

\subsection{Statistical Analysis}

We used logistic regression for our analysis. Logistic regression establishes the relationship between the dependent variable (health outcomes) and the independent variables (housing characteristics). It was appropriate for our analysis as the dependent variable is binary. It estimates the odds ratios used in interpreting the odds of being in the base category of health compared to being in the target category of health.

We took each health outcome as the dependent variable in the logistic regression. 'Continued experience of poor housing' was the main regressor. As covariates in the regression, we used the asset index (the total of 15 household assets), per capita income, gender, age, marital status, and the highest level of education. All models took the form:

Health outcome $e_{i}=\beta_{0}+\beta_{1}$ Continued experience of poor housing $+\beta_{2}$ Asset index $+\beta_{3}$ Per capita income $+\beta_{4}$ Gender $+\beta_{5}$ Age $+\beta_{6}$ Marital Status $+\beta_{7}$ Highest level of education $+\varepsilon$

All the $\beta$ s represent odds ratios, and the health outcomes are those in the 30 days before the survey in Wave 5 . The results of this analysis are presented in Tables 4 and 5 .

\subsection{Limitations}

There are four main weaknesses in our study. The first is that the health outcomes are self-reported, which introduces bias, and the second is the construction of the derived housing variables. The dummy variables capture those who experienced the housing condition continuously but do not capture how people transited from one housing condition to another. People might have moved from an informal house to a formal house (positive development), or they might have moved from a formal house to an informal house (negative development). A further weakness is the assumption that formal houses are always associated with better living standards and informal with worse. Thirdly, we use multivariate regression and not a true longitudinal method. Two reasons contributed to this decision. While the sample size appears large at first glance, the number of children 
in informal housing in any one wave remained small, and between waves there was very little movement of children in or out of informal housing. Further, the number of ill-health events, while varying by symptom, was small overall. Given the very small sample size for some subgroupings and the small observed effect sizes, the use of more complex forms of analysis was not feasible. Fourthly, panel surveys such as NIDS suffer from high sample attrition between survey waves. Attrition results from three cumulative factors: Mortality, migration between waves and survey non-response. In the NIDS data, of the 26,775 sample members interviewed in 2008, 15,673 were re-interviewed in all four subsequent waves, giving an attrition rate for the balanced panel of $41.47 \%$. For this study, the sample members in Wave 1 totaled 11,226 in 2008 and those who were successfully interviewed in Wave 5 totaled 9396 in 2018. For the 9396 sample members successfully interviewed in Wave 1, 6604 were successfully interviewed in Wave 2, 80 refused, 1008 were non-responses at the household level and 8 moved out of South Africa. This gave a Wave 1 to Wave 2 attrition rate of $29.71 \%$. Of the 1096 participants who were successfully interviewed in Wave 1 but fell to attrition in Wave 2, 966 (89.03\%) lived in formal dwellings while $119(10.97 \%)$ lived in informal dwellings.

Table 4. Housing and poor health outcomes in the past 30 days.

\begin{tabular}{|c|c|c|c|c|c|c|c|c|}
\hline \multicolumn{3}{|c|}{ Variables and Tests } & Fever & $\begin{array}{l}\text { Persistent } \\
\text { Cough }\end{array}$ & $\begin{array}{l}\text { Coughing } \\
\text { Blood }\end{array}$ & $\begin{array}{l}\text { Chest } \\
\text { Pain }\end{array}$ & $\begin{array}{l}\text { Body } \\
\text { Ache }\end{array}$ & Head Ache \\
\hline \multicolumn{3}{|c|}{ Number of observations } & 7637 & 7634 & 7635 & 7631 & 7629 & 7639 \\
\hline \multirow{3}{*}{ Model summary } & \multicolumn{2}{|c|}{ LR chi squared (14) } & 86.17 & 118.05 & 30.2 & 210.65 & 597.33 & 180.99 \\
\hline & \multicolumn{2}{|c|}{ Probability > chi squared } & 0.000 & 0.000 & 0.000 & 0.000 & 0.000 & 0.000 \\
\hline & \multicolumn{2}{|l|}{ Pseudo $\mathrm{R}^{2}$} & 0.010 & 0.022 & 0.048 & 0.053 & 0.088 & 0.019 \\
\hline \multicolumn{9}{|c|}{ Independent variables } \\
\hline \multirow{2}{*}{ Housing } & \multirow{2}{*}{$\begin{array}{l}\text { Continued experience } \\
\text { of poor housing }\end{array}$} & OR & 1.373 & 1.014 & 0.962 & 0.914 & 1.075 & 0.998 \\
\hline & & $p$ & 0.001 & 0.919 & 0.941 & 0.601 & 0.544 & 0.984 \\
\hline \multirow{2}{*}{ Asset index } & \multirow{2}{*}{ Asset index } & OR & 0.824 & 1.879 & 0.427 & 0.447 & 1.530 & 2.764 \\
\hline & & $p$ & 0.375 & 0.033 & 0.466 & 0.028 & 0.105 & 0.000 \\
\hline \multirow[b]{2}{*}{ Per capita income } & \multirow{2}{*}{ Income } & OR & 1000 & 1000 & 1000 & 1000 & 1000 & 1000 \\
\hline & & $p$ & 0.607 & 0.109 & 0.163 & 0.476 & 0.292 & 0.010 \\
\hline \multirow{2}{*}{ Gender } & \multirow{2}{*}{ Female } & OR & 1.284 & 1.096 & 0.502 & 1.146 & 1.320 & 1.556 \\
\hline & & $p$ & 0.000 & 0.249 & 0.021 & 0.171 & 0.000 & 0.000 \\
\hline \multirow{2}{*}{ Age } & \multirow{2}{*}{ Age } & OR & 1.012 & 1.022 & 1.021 & 1.024 & 1.037 & 1.012 \\
\hline & & $p$ & 0.000 & 0.000 & 0.000 & 0.000 & 0.000 & 0.000 \\
\hline \multirow{4}{*}{ Marital status } & \multirow{2}{*}{ Living with partner } & OR & 0.953 & 0.795 & 0.401 & 1.353 & 0.904 & 0.844 \\
\hline & & $p$ & 0.569 & 0.039 & 0.055 & 0.019 & 0.291 & 0.028 \\
\hline & \multirow{2}{*}{ Divorced/Separated } & OR & 0.864 & 0.761 & 0.452 & 1.183 & 1.178 & 0.863 \\
\hline & & $p$ & 0.148 & 0.038 & 0.108 & 0.265 & 0.130 & 0.111 \\
\hline \multirow{2}{*}{ Education } & \multirow{2}{*}{ Education } & OR & 1.002 & 0.985 & 0.904 & 0.976 & 0.990 & 0.998 \\
\hline & & $p$ & 0.779 & 0.167 & 0.014 & 0.051 & 0.277 & 0.932 \\
\hline \multirow{2}{*}{ Constant } & \multirow{2}{*}{ Constant } & OR & 0.239 & 0.061 & 0.235 & 0.038 & 0.041 & 0.200 \\
\hline & & $p$ & 0.000 & 0.000 & 0.000 & 0.000 & 0.000 & 0.000 \\
\hline
\end{tabular}

LR: likelihood ratio; OR: odds ratio. 
Table 5. Housing and poor health outcomes in the past 30 days.

\begin{tabular}{|c|c|c|c|c|c|c|c|c|}
\hline & Variables and Tests & & $\begin{array}{l}\text { Back } \\
\text { Ache }\end{array}$ & Arthritis & Diarrhoea & Dysuria & $\begin{array}{l}\text { Swollen } \\
\text { Ankles }\end{array}$ & Weight Loss \\
\hline \multirow{4}{*}{ Model summary } & \multicolumn{2}{|c|}{ Number of observations } & 7632 & 7635 & 7636 & 7631 & 7641 & 7630 \\
\hline & \multicolumn{2}{|c|}{ LR chi squared (14) } & 724.14 & 1471.56 & 28.51 & 30.66 & 336.05 & 45.8 \\
\hline & \multicolumn{2}{|c|}{ Probability > chi squared } & 0.000 & 0.000 & 0.000 & 0.000 & 0.000 & 0.000 \\
\hline & \multicolumn{2}{|l|}{ Pseudo $\mathrm{R}^{2}$} & 0.120 & 0.293 & 0.011 & 0.031 & 0.153 & 0.021 \\
\hline \multirow{2}{*}{ Housing } & \multirow{2}{*}{$\begin{array}{l}\text { Continued experience of } \\
\text { poor (unsuitable) housing }\end{array}$} & OR & 0.807 & 1.219 & 0.420 & 1.852 & 1.642 & 0.801 \\
\hline & & $p$ & 0.134 & 0.244 & 0.004 & 0.045 & 0.034 & 0.401 \\
\hline \multirow{2}{*}{ Asset index } & \multirow{2}{*}{ Asset index } & OR & 1.513 & 2.151 & 2.329 & 0.237 & 5.625 & 2.325 \\
\hline & & $p$ & 0.150 & 0.039 & 0.068 & 0.113 & 0.002 & 0.116 \\
\hline \multirow{2}{*}{ Per capita income } & \multirow{2}{*}{ Income } & OR & 1000 & 1000 & 1000 & 1000 & 1000 & 1000 \\
\hline & & $p$ & 0.040 & 0.569 & 0.145 & 0.059 & 0.028 & 0.019 \\
\hline \multirow{2}{*}{ Gender } & \multirow{2}{*}{ Female } & OR & 1.610 & 2.170 & 1.188 & 1.462 & 3.380 & 1.331 \\
\hline & & $p$ & 0.000 & 0.000 & 0.168 & 0.131 & 0.000 & 0.052 \\
\hline \multirow{2}{*}{ Age } & \multirow{2}{*}{ Age } & OR & 1.036 & 1.072 & 1.011 & 1.011 & 1.043 & 1.016 \\
\hline & & $p$ & 0.000 & 0.000 & 0.019 & 0.183 & 0.000 & 0.002 \\
\hline \multirow{4}{*}{ Marital status } & \multirow{2}{*}{ Living with partner } & OR & 1.250 & 1.010 & 0.886 & 0.759 & 1.747 & 1.106 \\
\hline & & $p$ & 0.027 & 0.938 & 0.489 & 0.417 & 0.003 & 0.594 \\
\hline & \multirow{2}{*}{ Divorced/Separated } & OR & 1.343 & 1.053 & 0.874 & 0.916 & 1.578 & 0.817 \\
\hline & & $p$ & 0.011 & 0.702 & 0.522 & 0.805 & 0.036 & 0.388 \\
\hline \multirow{2}{*}{ Education } & \multirow{2}{*}{ Education } & OR & 0.965 & 0.953 & 1.016 & 0.967 & 0.994 & 0.985 \\
\hline & & $p$ & 0.000 & 0.000 & 0.382 & 0.294 & 0.716 & 0.429 \\
\hline \multirow{2}{*}{ Constant } & \multirow{2}{*}{ Constant } & OR & 0.025 & 0.004 & 0.009 & 0.029 & 0.002 & 0.013 \\
\hline & & $p$ & 0.000 & 0.000 & 0.000 & 0.000 & 0.000 & 0.000 \\
\hline
\end{tabular}

LR: likelihood ratio; OR: odds ratio.

\section{Results}

Here we discuss the results of the logistic regression that were statistically significant at a $90 \%$ significance level. Tables 4 and 5 show the influence of housing on health outcomes 30 days before the survey in Wave 5. The pseudo $R^{2}$ was low, ranging from $1.0 \%$ (fever model) to $29.3 \%$ (arthritis model). Low pseudo $R^{2}$ can be interpreted the same way as $R^{2}$ (coefficient of determination) in linear regression, representing the variation of the dependent variable explained by the model. Because of the nature and complications of health models, a low pseudo $R^{2}$ is expected.

Four health indicators had a statistically significant relationship with the continued experience of poor housing. Participants who experienced this were more likely to have a fever $(\mathrm{OR}=1.373, p=0.001)$, dysuria $(\mathrm{OR}=1.852, p=0.045)$ or swollen ankles $(\mathrm{OR}=1.642$, $p=0.034)$ than those who did not have this experience. Care should be taken not to draw simplistic conclusions, as these symptoms could relate to poor water and sanitation. On the other hand, participants who had continued experience of poor housing were less likely to have diarrhoea $(\mathrm{OR}=0.420, p=0.004)$ than those who did not have this experience. This finding is contradictory to what was expected.

The asset index was statistically significant in six models. The odds of suffering from a symptom increased as the asset index increased: Persistent cough $(\mathrm{OR}=1.879, p=0.033)$, headache ( $\mathrm{OR}=2.764, p=0.000)$, arthritis $(\mathrm{OR}=2.151, p=0.039)$, diarrhoea $(\mathrm{OR}=2.329$, $p=0.068)$ and swollen ankles $(\mathrm{OR}=5.625, p=0.002)$. The likelihood of suffering from chest pain $(\mathrm{OR}=0.447, p=0.028)$ decreased as the asset index increased. These results thus show no direct relationship between socioeconomic status and health.

Five models showed a statistically significant relationship with per capita income: Headache $(\mathrm{OR}=1.000, p=0.010)$, backache $(\mathrm{OR}=1.000, p=0.040)$, dysuria $(\mathrm{OR}=1.000$, 
$p=0.059)$, swollen ankles (OR $=1.000, p=0.028)$ and weight loss $(\mathrm{OR}=1.000, p=0.019)$. Although the relationship is statistically significant, these results show that the likelihood of suffering from one of these symptoms increased marginally or did not increase at all with an increase in per capita income.

Eight statistically significant models were associated with gender. Women were more likely than men to suffer from fever $(\mathrm{OR}=1.284, p=0.000)$, body ache (1.320, $p=0.000)$, headache $(\mathrm{OR}=1.556, p=0.000)$, backache $(\mathrm{OR}=1.610, p=0.000)$, arthritis $(\mathrm{OR}=2.170, p=0.000)$, swollen ankles ( $\mathrm{OR}=3.380, p=0.000)$ or weight loss $(\mathrm{OR}=1.331$, $p=0.052)$. However, they were less likely to suffer from coughing blood than were their male counterparts $(\mathrm{OR}=0.502, p=0.021)$.

Age was statistically significantly associated with all the health outcome indicators except dysuria. For those that were significant, the likelihood of suffering from any poor health symptom increased as age increased. Previous studies have also found that age plays perhaps the most important role in the health profile of a population [30,31].

In terms of marital status, people living with partners were less likely than married people to suffer from persistent cough $(\mathrm{OR}=0795 . p=0.000)$, coughing blood $(\mathrm{OR}=0.401$, $p=0.055)$ or headache $(\mathrm{OR}=0.844, p=0.028)$. They were, however, more likely to suffer from chest pain $(\mathrm{OR}=1.353, p=0.019)$ or swollen ankles $(\mathrm{OR}=1.747, p=0.003)$. Divorced or separated persons were less likely than married people to suffer from persistent cough $(\mathrm{OR}=0.761 . p=0.038)$ and more likely to suffer from backache $(\mathrm{OR}=1.343, p=0.011)$ or swollen ankles $(\mathrm{OR}=1.578, p=0.036)$.

In terms of education, the statistically significant odds ratios were marginal, with all of them being close to one. An increase in education levels marginally decreased the likelihood of suffering from coughing blood ( $\mathrm{OR}=0.904, p=0.014)$, chest pain $(\mathrm{OR}=0.976$, $p=0.051)$, backache $(\mathrm{OR}=0.965, p=0.000)$ or arthritis $(\mathrm{OR}=0.953 . p=0.000)$.

\section{Discussion}

The world is urbanising rapidly, and WHO has estimated that the current urban population will double by 2050 [43]. This rapid urbanisation contributes to poor and informal housing. Improvement in housing might improve the quality of life, reduce poverty and improve health [41]. Given that informal houses are associated with poor health, policymakers could look at improvements in housing (inclusive of infrastructure) to deal with public health concerns.

The study's findings corroborate some international and national literature on the relationship between children's health and housing. On the one hand, the research results confirm the relationship of poor or unsuitable housing already found in some of the international literature [19]. We strengthen this finding by emphasising the long-term effects. The problem with most housing and health studies is that they only take one data point with respect to housing. By providing a history of poor or unsuitable housing, we look at the consequences over the long term. This is a shortcoming of most of the research in this field. We also confirm findings about the relationship between socioeconomic factors, housing and health. Some of the findings point to a relationship between household composition (for example the head of household being divorced or living with a partner and the educational status of the parent or care giver) that were also found in the international literature $[22,23,26]$. It is the relationship between unsuitable housing and diarrhoea that confirms previous African research [23]. However, we found cases that did not confirm the existing literature. For example, we found no statistical relationships with respect to crowding.

The inequality in housing represented in this paper results from two main causes: The historical exclusion of black people from urban areas and continued problems in providing and servicing informal settlements in South Africa. Under apartheid rule, the government prevented black people from urbanising [44]. When this restrictive policy started to change in the mid-1980s and free movement became possible in the 1990s, it contributed to a largescale influx of people to informal settlements across South Africa. The historical exclusion 
of black people from urban areas also meant their exclusion from the urban economy. Therefore, the housing inequalities described in the paper must be seen as part of the reality of South Africa being one of the world's most unequal countries. Yet there is also an indication that the post-apartheid government has not always embraced urbanisation [45]. Consequently, appropriate urbanisation and informal settlement-upgrade planning have not been adequate.

The WHO states that housing quality has major implications for people's health, and poor housing conditions are an important determinant of health outcomes [42]. People in our sample who had lived in inadequate housing for prolonged periods (in four or five of the five NIDS waves) had poorer health outcomes for a selection of health indicators. These results align with a study by Kreiger and Higgins that found significant differences in health outcomes between people who had continuous experience of poor housing and those who did not [17]. Our results show that housing can contribute to health inequity in the long term. The value of our study lies in the longitudinal nature of the data, which differs considerably from cross-sectional data. Methodologically, it emphasises the effects of long-term inadequate housing.

Despite the findings discussed above, the main mechanism of poor health is not always clear. The data points to many factors and covariables, other than housing, playing a role. For example, most people living in informal housing do not have ready access to water and sanitation. Earlier work by Marais and Cloete found that the quality of services is the main driver of poor health [30]. Thus, although our study considered inadequate housing, it might indirectly point to insufficient access to services and poor quality of services. Improved infrastructural services (clean water and sanitation) are also important for informal settlement upgrading programmes in South Africa. However, the informal settlement upgrading programme has been slow to take off and does not always follow the programme guidelines [45]. Mainstreaming the informal settlement upgrading programme could help in addressing poor access to infrastructure services.

Overall, there are two ways to improve housing conditions in South Africa: Build new houses for people and upgrade informal settlements. Upgrading might not necessarily lead to improved housing structures but it could improve infrastructure. The South African government has several housing programmes. These have slowed down due to funding constraints. Building new houses has proved an expensive and demanding task for the government and also costly for individuals. Most people living in informal settlements are low-income earners. Besides housing, the government needs to devote attention to providing adequate services. Yet, in addition to these larger policy programmes, support and care programmes can do more to make people aware of the relationship between housing and health. For example, the Department of Social Development has several community outreach programmes to address the role of good housing regarding children's health. Community-health care workers can perform the same role. For example, healthcare workers can make parents and care workers aware of tuberculosis.

In addition to the potential role of housing structure, a broader framework should be considered. According to $\mathrm{WHO}$, a people-centred health system framework comprises six building blocks: Leadership and governance, health information systems, health financing, health service delivery, human resources and medicines and technology [12]. These building blocks must link to the social policies identified in WHO's framework shown in Figure 1. In particular, health systems service delivery must be connected to housing as health services must be accessible.

\section{Conclusions}

Our study identified some relationships between housing conditions and health outcomes using a longitudinal approach. This approach contrasts with cross-sectional work, where the research findings are often context specific. Because of collinearity between the three variables designed to measure housing characteristics we originally considered from the literature, only a continued experience of poor housing was used in this study 
as an independent variable in the logistic regression equation. The results indicate the difficulty of isolating and examining the relationship between housing and health. The relationship does exist, as the models are significant, but the strength of the relationship is weak, as shown by the low $R^{2}$. Where the model is significant, the results are mixed.

The paper adds to the literature on the complex relationships between housing and health. It emphasises the importance of longitudinal research and recording the possible health effects of inadequate housing over time. Although this is not the first time this approach has been followed, it is the first time it has been performed in South Africa. However, we should be careful not to think about informal housing only in terms of the housing structure. Informal housing also implies poor access to water and sanitation. Our results call for a closer consideration of housing to address public health concerns

Author Contributions: Conceptualization, L.M., K.C. and J.C.; methodology, J.C. and K.C. software, J.C. and K.C.; validation, K.C. and J.C.; formal analysis, K.C.; investigation, K.C, J.C and L.M.; resources, K.C.; data curation, J.C and K.C; writing—original draft preparation, K.C.; writing—review and editing, L.M.; visualization, K.C.; supervision, L.M.; project administration, L.M.; funding acquisition, K.C. All authors have read and agreed to the published version of the manuscript.

Funding: This research received no external funding.

Institutional Review Board Statement: The study was conducted in accordance with the Declaration of Helsinki and approved by the General Human Research Ethics Committee of the University of the Free State. Application number: UFS-HSD2021/0371/21. Date of approval: 28 June 2021.

Informed Consent Statement: This study utilised anonymised secondary data from a data repository.

Data Availability Statement: Data can be obtained from: http:/ / www.nids.uct.ac.za/.

Conflicts of Interest: The authors declare no conflict of interest.

\section{References}

1. Howden-Chapman, P. Housing standards: A glossary of housing and health. J. Epidemiol. Community Health 2004, 58, 162-168. [CrossRef] [PubMed]

2. Gifford, R.; Lacombe, C. Housing quality and children's socioemotional health. J. Hous. Built Environ. 2006, 21, 177-189. [CrossRef]

3. Solari, C.; Mare, R. Housing crowding effects on children's well-being. J. Soc. Sci. Res. 2012, 41, 464-476. [CrossRef] [PubMed]

4. Pierse, N.; Carter, K.; Bierre, S.; Law, D.; Howden-Chapman, P. Examining the role of tenure, household crowding and housing affordability on psychological distress, using longitudinal data. J. Epidemiol. Community Health 2016, 70, 961-966. [CrossRef] [PubMed]

5. Wang, S.; Cheng, C.; Tan, S. Housing determinants of health in urban China: A structural equation modelling analysis. Soc. Indic. Res. 2018, 143, 1245-1270. [CrossRef]

6. Magee, C.; Norena, M.; Hubley, A.; Palepu, A.; Hwang, S.; Nisenbaum, R.; Karim, M.; Gadermann, A. Longitudinal associations between perceived quality of living spaces and health-related quality of life among homeless and vulnerably housed individuals living in three Canadian cities. Int. J. Environ. Res. Public Health 2019, 16, 4808. [CrossRef]

7. Rhoades, H.; Wenzel, L.; Henwood, B. Changes in self-rated physical health after moving into permanent supportive housing. Am. J. Health Promot. 2019, 33, 1073-1076. [CrossRef]

8. Tusting, L.; Gething, P.; Gibson, H.; Greenwood, B.; Knudsen, J.; Lindsay, S.; Bhatt, S. Housing and child health in sub-Saharan Africa: A cross-sectional analysis. PLoS Med. 2020, 17, e1003055. [CrossRef]

9. Mallet, S.; Bentley, R.; Baker, E.; Mason, K.; Keys, D.; Kolar, V.; Krnjacki, L. Precarious Housing and Health Inequalities: What Are the Links? Summary Report; Hanover Welfare Services; University of Melbourne: Melbourne, Australia, 2011.

10. World Health Organisation. Constitution of the World Health Organisation. 1946. Available online: https://www.who.int/ about/governance/constitution (accessed on 12 November 2021).

11. World Health Organisation. Social Determinants of Health. 2021. Available online: https://www.who.int/health-topics/socialdeterminants-of-health\#tab=tab_3 (accessed on 12 November 2021).

12. World Health Organisation. A Conceptual Framework for Action on the Social Determinants of Health. Social Determinants of Health Discussion Paper 2; WHO: Geneva, Switzerland, 2010.

13. Thompson, H.; Petticrew, M. Is Housing Improvement a Potential Health Improvement Strategy? Health Evidence Network Report; WHO Regional Office for Europe: Copenhagen, Denmark, 2005.

14. Thomas, H.; Thomas, S. Developing empirically supported theories of change for housing investment and health. J. Soc. Sci. Med. 2015, 124, 205-214.

15. Marsh, A.; Gordon, D.; Heslop, P.; Pantazis, C. Housing deprivation and health: A longitudinal study. Hous. Stud. 2000, 15, 411-428. [CrossRef] 
16. Gan, W.; Sanderson, W.; Browning, S.; Mannino, D. Different types of housing and respiratory outcomes. Prev. Med. Rep. 2017, 7, 124-129. [CrossRef] [PubMed]

17. Kreiger, J.; Higgins, D. Housing and health: Time again for public health action. Am. J. Public Health 2002, 92, 758-768. [CrossRef] [PubMed]

18. Ingham, T.; Keall, M.; Jones, B.; Aldridge, D.; Dowell, A.; Davies, C.; Crane, J.; Draper, J.; Bailey, L.; Viggers, H.; et al. Damp mouldy housing and early childhood hospital admissions for acute respiratory infection: A case-control study. Thorax 2019, 74, 849-857. [CrossRef] [PubMed]

19. Oudin, A.; Richter, J.C.; Taj, T.; Al-nahar, L.; Jakobsson, K. Poor housing conditions in association with child health in a disadvantaged immigrant population: A cross-sectional study in Rosengård, Malmö, Sweden. BMJ Open 2016, 6, e007979. [CrossRef] [PubMed]

20. Alley, D.; Lloyd, J.; Pagan, J.; Pollack, C.; Shardell, M.; Cannuscio, C. Mortgage delinquency and changes in access to health resources and depressive symptoms in a nationally representative cohort of Americans older than 50 years. Am. J. Public Health 2011, 101, 2293-2298. [CrossRef] [PubMed]

21. Blackburn, C. Poverty and Health: Working with Families; Open University Press: Milton Keynes, UK, 1990.

22. Leventhal, T.; Newman, S. Housing and child development. Child. Youth Serv. Rev. 2010, 32, 1165-1174. [CrossRef]

23. Ntshebe, O.; Channon, A.; Hosegood, V. Household composition and child health in Botswana. BMC Public Health 2019, 19 , 1621. [CrossRef]

24. Skobba, K.; Goetz, E. Doubling up and the erosion of social capital among very low-income households. Int. J. Hous. Policy 2015, 15, 127-147. [CrossRef]

25. Evans, G. The built environment and mental health. J. Urban Health 2003, 80, 536-555. [CrossRef]

26. Dockery, M.; Ong, R.; Colquhoun, S.; Li, J.; Kendall, G. Housing and Children's Development and Well-Being: Evidence from Australian Data; AHURI Final Report No. 201; Australian Housing and Urban Research Institute: Melbourne, Australia, 2013.

27. Coley, R.; Leventhal, T.; Lynch, A.; Kull, M. Relations between housing characteristics and the well-being of low-income children and adolescents. Dev. Psychol. 2013, 49, 1775-1789. [CrossRef]

28. Fry, C. Executive Functions, Creativity, and Mental Health in Homeless Young People: Implications for Housing Outcome. Ph.D. Thesis, Cardiff University, Cardiff, UK, 2018.

29. Govender, T.; Barnes, J.; Pieper, C. Housing conditions, sanitation status and associated health risks in selected subsidised low-cost housing settlements in Cape Town, South Africa. Habitat Int. 2011, 35, 335-342. [CrossRef]

30. Marais, L.; Cloete, J. 'Dying to get a house?' The health outcomes of the South African low-income housing programme. Habitat Int. 2014, 43, 48-60. [CrossRef]

31. Mathee, A.; Barnes, B.; Naidoo, S.; Swart, A.; Rother, H. Development for children's environmental health in South Africa: Past gains and future opportunities. Dev. S. Afr. 2018, 35, 283-293. [CrossRef]

32. Nkosi, V.; Haman, T.; Naicker, N.; Mathee, A. Overcrowding and health in two impoverished suburbs of Johannesburg, South Africa. BMC Public Health 2019, 19, 1358. [CrossRef]

33. Shortt, N.; Hammett, D. Housing and health in an informal settlement upgrade in Cape Town, South Africa. J. Hous. Built Environ. 2013, 28, 615-627. [CrossRef]

34. De Wet, T.; Plagerson, S.; Harpham, T.; Mathee, A. Poor housing, good health: A comparison of formal and informal housing in Johannesburg, South Africa. Int. J. Public Health 2011, 56, 625-633. [CrossRef]

35. Muyeba, S. Effects of Government Housing Subsidies in Khayelitsha, Cape Town; Working Paper No. 346; CSSR (Centre for Social Science Research), University of Cape Town: Cape Town, South Africa, 2014.

36. Shisana, O.; Rehle, T.; Simbayi, L.C.; Zuma, K.; Jooste, S.; Zungu, N.; Labadarios, D.; Onoya, D. South African National HIV Prevalence, Incidence and Behaviour Survey, 2012; HSRC (Human Sciences Research Council): Pretoria, South Africa, 2014.

37. Gibbs, A.; Govender, K.; Jewkes, R. An exploratory analysis of factors associated with depression in a vulnerable group of young people living in informal settlements in South Africa. Glob. Public Health 2016, 13, 788-803. [CrossRef]

38. Marais, L.; Sharp, C.; Pappin, M.; Lenka, M.; Cloete, J.; Skinner, D.; Serekoane, J. Housing conditions and mental health of orphans in South Africa. Health Place 2013, 24, 23-29. [CrossRef]

39. Hunt, S. Damp and mouldy housing; a holistic approach. In Unhealthy Housing; Burridge, R., Ormandy, D., Eds.; Taylor \& Francis: London, UK, 1993.

40. Wilkinson, D. Poor Housing and Ill Health: A Summary of Research Evidence; The Scottish Office, Central Research Unit: Edinburgh, UK, 1999.

41. World Health Organisation. Review of housing and health risks. In Health Co-Benefits of Climate Change Mitigation-Housing Sector: Health in the Green Economy; Fletcher, E.R., Ed.; WHO: Geneva, Switzerland, 2010; pp. 29-41.

42. United Nations Children's Fund. Convention on the Rights of the Child. 1989. Available online: https://www.unicef.org/childrights-convention/ convention-text (accessed on 15 September 2021).

43. World Health Organisation. Housing and Health Guidelines; WHO: Geneva, Switzerland, 2018.

44. Mabin, A. Dispossession, exploitation and struggle: An historical overview of South African urbanization. In The Apartheid City and Beyond: Urbanisation and Social Change in South Africa; Smith, D., Ed.; Routledge: London, UK, 1992; pp. 13-24.

45. Huchzermeyer, M. A critical Lefebvrian perspective on planning in relation to informal settlements in South Africa. Town Reg. Plan. 2021, 79, 44-54. [CrossRef] 